\title{
Mesenchymal Stem Cells, Used As Bait, Disclose Tissue Binding Sites
}

\section{A Tool in the Search for the Niche?}

\author{
Brian B. Ratliff, ${ }^{*}$ Nandita Singh, ${ }^{*}$ Kaoru Yasuda, ${ }^{*}$ \\ Hyeong-Cheon Park, ${ }^{*}$ Francesco Addabbo, ${ }^{*}$ \\ Tammer Ghaly, ${ }^{*}$ Maharshi Rajdev, ${ }^{*}$ \\ Jean-Francois Jasmin, ${ }^{\dagger}$ Matthew Plotkin, ${ }^{*}$ \\ Michael P. Lisanti, ${ }^{\dagger}$ and Michael S. Goligorsky ${ }^{\star}$ \\ From the Departments of Medicine and Pharmacology, ${ }^{*}$ Renal \\ Research Institute, New York Medical College, Valhalla, New \\ York, and the Kimmel Cancer Center, ${ }^{\dagger}$ Thomas Jefferson \\ University, Philadelphia, Pennsylvania
}

We developed an ex vivo approach characterizing renal mesenchymal stem cell (MSC) adhesion to kidney sections. Specificity of MSC adhesion was confirmed by demonstrating a) 3T3 cells displayed 10fold lower adhesion, and b) MSC adhesion was CXCR4/stromal-derived factor-1 (SDF-1)-dependent. MSC adhesion was asymmetrical, with postischemic sections exhibiting more than twofold higher adhesion than controls, and showed preference to perivascular areas. Pretreating kidney sections with cyclic arginine-glycine-aspartic acid peptide resulted in increased MSC adhesion (by displacing resident cells), whereas blockade of CXCR4 with AMD3100 and inhibition of $\alpha 4 \beta 1$ (VLA4) integrin or vascular cellular adhesion molecule- 1 , reduced adhesion. The difference between adhered cells under cyclic arginine-glycine-aspartic acid peptide-treated and control conditions reflected prior occupancy of binding sites with endogenous cells. The AMD3100-inhibitable fraction of adhesion reflected CXCR4-dependent adhesion, whereas maximal adhesion was interpreted as kidney MSC-lodging capacity. MSC obtained from mice overexpressing caveolin-1 exhibited more robust adhesion than those obtained from knockout animals, consistent with CXCR4 dimerization in caveolae. These data demonstrate a) CXCR4/ SDF-1-dependent adhesion increases in ischemia; b) CXCR4/SDF-1 activation is dependent on MSC surface caveolin-1; and c) occupancy of MSC binding sites is decreased, while d) capacity of MSC binding sites is expanded in postischemic kidneys. In conclusion, we developed a cell-bait strategy to unmask renal stem cell binding sites, which may potentially shed light on the MSC niche(s) and its characteristics. (Am J Pathol 2010, 177:873-883; DOI: 10.2353/ajpath.2010.090984)

The concept of a stem cell niche is 30 years old ${ }^{1}$ and yet adult stem cell niches remain elusive. The best-studied niches are represented by those harboring germline stem cells, bone marrow hematopoietic stem cells, and stem cells of intestinal crypts, to name a few. ${ }^{2-4}$ Consensus exists that stem cell niches provide an umbrella microenvironment supporting cell attachment and quiescence by sheltering cells from proliferation and differentiation signals, enhancing cell survival, and regulating stem cell division and renewal, as well as coordinating the population of resident stem cells to meet the actual requirements of an organ. ${ }^{2}$ Zhang et al ${ }^{5}$ and Calvi et $\mathrm{al}^{6}$ have disclosed complex relations within the bone marrow osteoblastic-hematopoietic stem cell niche with its intricate regulation by parathyroid hormone and bone morphogenetic protein. These studies have ignited the renewed interest and the search for other niches hypothetically present in each peripheral organ throughout adulthood. ${ }^{7}$ In the kidney, Oliver et al ${ }^{8}$ have demonstrated that labelretaining cells are predominantly localized to the renal papilla, the site characterized by the reduced oxygen

Supported in part by National Institute of Health grants DK54602, DK052783, and DK45462 M.S.G. and Westchester Artificial Kidney Foundation.

Accepted for publication April 27, 2010.

Supplemental material for this article can be found on http://ajp. amjpathol.org.

A guest editor acted as editor-in-chief for this manuscript. No person at Thomas Jefferson University or Albert Einstein College of Medicine was involved in the peer review process or final disposition for this article.

Address reprint requests to Michael S. Goligorsky, M.D., Ph.D., New York Medical College, Renal Research Institute - Basic Sciences Building Room \#C06, 15 Dana Road, Valhalla, NY 10595. E-mail: Michael_ goligorsky@nymc.edu. 
tension, from where they are capable of migrating toward the sites of injury. In addition, Maeshima et $\mathrm{al}^{9}$ and Challen et $\mathrm{al}^{10}$ advocated the existence of a cortical tubular pool of stem cells, suggesting the existence of another niche in the kidney. Patschan et al ${ }^{11}$ working with nestin-green fluorescent protein (GFP) mice demonstrated that nestin-positive cells, some of which are presumed to be mesenchymal stem cells (MSCs), are enriched in the renal medulla and exhibit ability to migrate toward the renal cortex. These and other studies, although suggestive of the existence of stem cell niches in the adult organ, have a limitation of not being able to directly and unequivocally detect these compartments. For instance, one of the broadly used markers of stem cell compartment, DNA label retention, has been disputed based on the possibility of an "immortal DNA strand" which suggests that a labeled strand is retained in the stem cell despite its division. ${ }^{12}$

There are several known adhesion molecules identified in hematopoietic stem cell niches (E-selectin, vascular cellular adhesion molecule [VCAM]-1, uPAR, hyaluronan, stromalderived factor-1, [SDF]-1, osteopontin, Kit ligand, N-cadherin, and $\beta$-catenin, to name a few), but they are not specific for the niche compartment. ${ }^{13}$ Yet, it has been previously shown that SDF-1 is necessary for adhesion of CXCR4-expressing cells and that adhesive interactions between hematopoietic stem cell and stromal cells are mediated in part through $\alpha 4 \beta 1$ (VLA4)NCAM- 1 interaction. ${ }^{14}$ In this vein, inducible ablation of $\alpha 4 \beta 1$ (VLA4) or conditional ablation of its partner, VCAM-1, are both associated with the enhancement of granulocyte-colony stimulating factor-induced mobilization of hematopoietic stem cell. ${ }^{15-17}$ Moreover, stem/progenitor cell recruitment into neovasculature was found to be $\alpha 4 \beta 1$ (VLA4)/NCAM-1-dependent. ${ }^{18}$ In our previous studies of monocyte-to-endothelial cell adhesion, we demonstrated, using atomic force microscopy, the potency of cyclic arginine-glycine-aspartic acid peptide (cRGD) peptide in inhibiting cell-cell interactions ${ }^{19}$ in large part due to the inhibition of adhesion between $\alpha 4 \beta 1$ (VLA4)/ VCAM-1 partners. Based on the existing technological gap in detecting stem cell niches, we inquired whether binding characteristics of stem cells presented as bait could be exploited for this purpose.

Here, we attempted to explore these adhesive properties of stem cell-to-renal parenchyma interaction by monitoring MSC adhesion under (a) baseline conditions, (b) following application of an inhibitor of CXCR4, conditions modulating homodimerization of CXCR4 or neutralizing antibodies against VLA4, VCAM-1, and N-cadherin, and (c) after displacement of stem cells preoccupying the existing binding sites by interfering with the $\alpha 4 \beta 1$ (VLA4)NCAM-1-mediated adhesion, as well as examined (d) the potential capacity of MSC binding sites after ischemic insult.

\section{Materials and Methods}

\section{Animal Models and Surgical Procedures}

The animal study protocol was in accordance with the National Institutes of Health Guide for the Care and Use of
Laboratory Animals ${ }^{20}$ and approved by the Institutional Animal Care and Use Committee. Tie-2-GFP mice were obtained from Jackson Labs (Bar Harbor, ME). Tie-2-GFP mice express GFP, driven by an endothelial-specific and selective promoter for the Tie-2 receptor, resulting in specific fluorescence of endothelial cells and their progenitor cells, as previously described. ${ }^{21}$ Sca-1-GFP mice ${ }^{22}$ were used for detection of cell displacement after treatment with the CRGD peptide.

All animals were separately caged with a 12-hour lightdark cycle and had free access to water and food throughout the study. To prevent vascular thrombosis, a subcutaneous injection of $250 \mathrm{U} / \mathrm{kg}$ heparin was given 15 minutes before operations. Animals were anesthetized before surgery with an intraperitoneal injection of ketamine (2 $\mu \mathrm{g} / \mathrm{g}$ of body weight) and xylazine (23 $\mu \mathrm{g} / \mathrm{g}$ of body weight). A $1.5-\mathrm{cm}$ flank incision was made to expose the left kidney. The left renal artery was clamped with microserrefines (Fine Science Tools, Foster City, CA). After 30 minutes, the clamp was released and the flank incision was closed with 4-0 suture (Superion, Cincinnati, $\mathrm{OH})$. At various time points after surgery $(1,3,5$, and 7 days), mice were sacrificed, perfused with PBS through the left ventricle, and both right and left kidneys were collected. For subsequent experiments, right side kidneys were used as controls while left side kidneys were ischemic. Excised kidneys were immediately sectioned into 500 to 600 um coronal sections containing the entire cortical and medullary parenchyma. Sections were immediately placed in minimum essential medium (Gibco/Invitrogen, Grand Island, NY) with 10\% horse serum (Gem Biotech, Woodland, CA) and $0.1 \mathrm{~mol} / \mathrm{L}$ HEPES (Sigma, St. Louis, MO), stem cells and necessary reagents added, and adhesion assay proceeded under a gentle shaking.

\section{Isolation and Culture of MSC-4E Cells, Endothelial Progenitor Cells and Fibroblasts}

Using a technique for culturing multipotent mesenchymal cells from adult tissues, ${ }^{23-25}$ we have previously isolated and cloned a multipotent cell line (referred to as MSC-4E) from the kidney of adult Tie-2 GFP mice. ${ }^{21}$ These MSC-4E cells could be differentiated along multiple mesodermal lineages, including adipocytes, chondrocytes, and osteoblasts, as well as endothelial cells. Analysis of the expression of surface antigens, growth factor receptors, cytoskeletal proteins, and transcription factors revealed a pattern that was compatible with both mouse MSCs and renal stromal progenitor cells. ${ }^{21}$ MSC-4E cells were maintained on gelatin-coated dishes in minimal essential medium with 10\% horse serum (Invitrogen, Grand Island, NY) and consistently expressed MSC markers between passages 10 and 25. For comparative studies, primary MSC cultures were obtained from Tie-2 GFP mice using the same techniques. ${ }^{21}$ 3T3 fibroblasts and endothelial progenitor cells (EPC) were used as controls for nonspecific adhesion.

To isolate EPC, femurs of FVB/NJ mice were flushed with PBS and the flow-through solution was subject to 
density gradient centrifugation with Histopaque-1077 (Sigma Chemical Co., St. Louis, MO) for cell separation. Bone marrow mononuclear cells were cultured in Mouse Endothelial Progenitor Cell Culture Serum Free Media (Celprogen, San Pedro, CA) on dishes coated with 10 $\mu \mathrm{g} / \mathrm{ml}$ pronectin (Sigma, St Louis, MO). After 3 days in culture, nonadherent cells were removed, and medium was exchanged every 2 days. Prepared cells were further characterized to ensure the purity of EPC population (>95\% of cells were labeled by the following markers) by 1) uptake of dil-labeled acetylated low density lipoprotein $(2.4 \mu \mathrm{g} / \mathrm{ml}$ of dil-actylated low density lipoprotein, Biomedical Technologies, Inc., Stoughton, MA), and 2) lectin binding $(25 \mu \mathrm{g} / \mathrm{ml}$ of Fluorescein-Ulex Europeus Lectin, Biomeda Corp., Forster City, CA).

\section{Pretreatment of Kidney Sections}

Control and ischemic kidney sections were pretreated with vehicle (minimum essential medium alone), AMD3100 (Sigma, St. Louis, MO), or cRGD (Peptide Institute, Inc., Osaka, Japan). AMD3100 was added to kidney sections at a concentration of $1 \mu \mathrm{g} / \mathrm{ml}$. The choice of concentration of AMD3100 was selected in accord with previously published data. ${ }^{22} \mathrm{CRGD}$ was added to kidney sections at a concentration of $10 \mu \mathrm{mol} / \mathrm{L}$. The concentration of CRGD used in the assay was based on previous studies demonstrating its ability to inhibit $\alpha 4 \beta 1$ (VLA4)/ VCAM-1-mediated adhesion. ${ }^{19}$ After introduction of either AMD3100 or CRGD, kidney sections were incubated for 30 minutes on ice before addition of MSC-4E cells and maintained in medium for the entire duration of the experiment. For inhibition studies using function-blocking antibodies against VLA4 (Southern Biotech, Birmingham, AL), N-cadherin (Sigma, St. Louis, MO), and VCAM-1 (Abcam, Cambridge, MA), each neutralizing antibody was added to kidney section medium before introduction of MSC-4E cells and maintained in the medium during the entire assay period. Concentrations of neutralizing antibodies used were $25 \mu \mathrm{g} / \mathrm{ml}$ for VLA4 and N-cadherin and $50 \mu \mathrm{g} / \mathrm{ml}$ for VCAM- 1 .

Before adhesion assay, cells were labeled with CellTracker CM-Dil (Molecular Probes, Eugene, OR). In brief, cells were lifted by trypsinization, washed, and then incubated with CellTracker (per manufactures protocol) at $37^{\circ} \mathrm{C}$ for 30 minutes. Cells were placed on ice for 10 minutes (to stop endocytosis of the fluorophore), washed, and resuspended in minimum essential medium with 10 mmol/L HEPES. MSCs were counted using a hemocytometer (Cole-Parmer, Vernon Hills, IL).

\section{Cell Presentation to Kidney Sections and Adhesion Assay}

The duration of presentation of stem cells to kidney sections during the adhesion assay (see Supplemental Figure 1 at $h$ ttp://ajp.amjpathol.org), and the number of stem cells used for presentation, were selected in preliminary experiments conducted to optimize the assay. Preliminary experiments indicated that $5 \times 10^{3}$ cells were the optimal quantity of MSC-4E cells for presentation. An incubation time of 120 minutes was selected as optimal based on preliminary experiments using incubation times ranging from 1 to 4 hours.

Kidney sections pretreated with vehicle, AMD3100, or CRGD were maintained in chamber slides (Nalge Nunc, Inc., Naperville, IL) and cells were presented to kidney sections by adding them directly into the incubation medium. Sections presented with stem cells were incubated at $37^{\circ} \mathrm{C}$ on a shaker (New Brunswick Scientific, Edison, $\mathrm{NJ}$ ) at $50 \mathrm{rpm}$ for 2 hours. After 2 hours, kidney sections were washed with basal medium to remove nonadhered cells and fixed with $4 \%$ paraformaldehyde solution (Electron Microscopy Sciences, Hatfield, PA). Following subsequent washing, cell adhesion to kidney sections was examined using a Nikon compound fluorescence microscope with the appropriate dichroic mirrors (Nikon, Melville, NY). Adhered cells were counted at $\times 10$ magnification. Cell adhesion was evaluated separately for cortical and medullary zones and renal capsule within each kidney section. Cell counts were presented as the number of cells per $4 \mathrm{~mm}^{2}$ surface area. In addition, kidney sections were permeabilized with $0.5 \%$ Triton (Sigma), subjected to antigen retrieval with incubation in $100 \mathrm{mmol} / \mathrm{L}$ citrate buffer, and stained for fibronectin (Abcam), SDF-1 (eBiosciences, San Diego, CA), CD29 (BD Pharmingen, San Jose, CA), and CD44 (BD Pharmingen) using manufacturer's recommendations.

To determine whether MSC-4E cell adhesion to ischemic tissue was altered by preconditioning of cells, $4 \mathrm{E}$ cells were subjected to either 24 hours of hypoxic preconditioning (using cell culture hypoxic chambers with inclusion of 15 $\mathrm{mmol} / \mathrm{L} \mathrm{HEPES}$ into the culture medium) or pretreatment with tumor necrosis factor- $\alpha(50 \mathrm{ng} / \mathrm{ml})$ (Sigma) applied to the serum free culture medium for 24 hours. After pretreatment of MSC-4E cells, the cells were used routinely in the cell adhesion assay, as previously described here.

The adhesion assay was used on sections of the heart tissue, in addition to kidneys. BALB/C mice were injected intravenously with a one time dose of adriamycin (10.2 $\mathrm{mg} / \mathrm{kg}$ ) (Sigma) to induce cardiomyopathy and sacrificed 2 weeks later. On sacrifice, hearts were removed, sectioned, and immediately subjected to the adhesion assay following the same protocol as used with kidney tissue.

\section{cRGD Displacement of Sca-1-Positive Cells}

The colony-forming unit assay was performed according to the previously described protocol by Stemcell Technologies. Briefly, kidney sections from Sca-1 GFP mice were incubated in the presence of $10 \mu \mathrm{mol} / \mathrm{L}$ CRGDcontaining medium for 2 hours to displace endogenous MSC. Medium was harvested, treated with $3 \%$ acetic $\mathrm{acid} /$ methylene blue (Stemcell Technologies, Vancouver, Canada), and $1 \times 10^{3}$ cells from the medium were plated on $0.1 \%$ gelatin coated dishes. Cells were cultured in MesenCult Medium (supplemented with Mesenchymal Stem Cell Stimulatory Supplement, Stemcell Technologies). After 2 weeks, cells were stained with Giemsa stain (Stemcell Technologies) and the number of colonies (>50 cells) co-expressing Sca-1 GFP were counted. 
To confirm that displaced cells were indeed authentic MSC, displaced cells that formed colonies were treated with differentiating medium to demonstrate their osteogenic and adipogenic potential. For osteogenic induction, cells were treated for 3 weeks with Dulbecco's modified Eagle medium (Invitrogen) (low glucose) supplemented with 10\% fetal bovine serum (Invitrogen), $0.1 \mu \mathrm{mol} / \mathrm{L}$ dexamethasone (Sigma), $50 \mu \mathrm{mol} / \mathrm{L}$ ascorbic acid-2-phosphate (Sigma), and $10 \mathrm{mmol} / \mathrm{L} \beta$-glycerophosphate (Sigma). Alkaline phosphatase activity was visualized by staining with $0.6 \mathrm{mg} / \mathrm{ml}$ napthol AS-BI phosphate (Sigma) and $0.1 \mathrm{mg} / \mathrm{ml}$ fast red TR salt (in $0.1 \mathrm{~mol} / \mathrm{L}$ Tris- $\mathrm{HCl}[\mathrm{pH} 8.5]$ with $50 \mathrm{mmol} / \mathrm{L} \mathrm{MgCl}_{2}$ ) (Sigma). To demonstrate the presence of calcium phosphate, von Kossa staining was used which included treating cells with $5 \%$ silver nitrate (Sigma) in front of UV light for 30 minutes followed by washing with $5 \%$ sodium thiosulphate (Sigma). For adipogenic induction, cells were treated for 3 weeks with Dulbecco's modified Eagle medium (high glucose) supplemented with 10\% fetal bovine serum, $1 \mu \mathrm{mol} / \mathrm{L}$ dexamethasone, $0.2 \mathrm{mmol} / \mathrm{L}$ indomethacin (Sigma), 10 $\mu \mathrm{g} / \mathrm{ml}$ insulin (Sigma), and $0.5 \mathrm{mmol} / \mathrm{L}$ 3-isobutyl-I-methylxanthin (Sigma) for 3 days followed by maintenance using adipogenesis maintenance medium composed of Dulbecco's modified Eagle medium (high glucose), 10\% fetal bovine serum, and $10 \mu \mathrm{g} / \mathrm{ml}$ insulin for 4 days. Adipogenic differentiation was assessed using oil red $\mathrm{O}$ stain $(0.3 \%$ oil red $\mathrm{O}$ stain in isopropanol) (Sigma).

\section{Cav-1 and ex Vivo Cell Adhesion Assay}

Transgenic mice overexpressing caveolin-1 (Cav-1 TG) and caveolin-1 knockout mice (Cav-1 KO) were used to obtain additional MSC for use in the ex vivo cell adhesion assay. In brief, MSC from Cav-1 TG, Cav-1 KO, and wild-type FVB/NJ were isolated and cultured as previously described. ${ }^{40}$ Control or postischemic kidneys (3 days postischemia) from wild-type mice were removed, sectioned, and presented with MSC isolated from Cav-1 TG, Cav-1 KO, and wild-type mice in the cell adhesion assay.

\section{Flow Cytometry Analysis}

MSC-4E cells were analyzed for surface expression of VLA4 using FACS analysis. Cells were stained with rat anti-mouse VLA4 (Abcam) primary antibody, dilution 1:250, followed by fluorescein isothiocyanate-conjugated goat anti-rat secondary antibody (Jackson ImmunoResearch, West Grove, PA). Cells were co-stained with 7-aminoactinomyosin D (Invitrogen). After staining, cells were fixed with $4 \%$ paraformaldehyde and subjected to fluorescence-activated cell sorting analysis. Data were acquired using a FACScan cytometer equipped with a 488-nm argon laser and a 620-nm red diode laser and analyzed using CellQuest software (Becton Dickinson, San Jose, CA). The setup of FACScan was performed using unstained and secondary antibody-stained cells.

\section{Statistical Analysis}

Data are presented as means \pm SEM. For multiple comparisons between groups, a two-way analysis of variance

with Bonferroni's post test was performed. For other comparisons, a one-way analysis of variance with Tukey's post test was performed. All statistical analysis was performed using GraphPad Prism version 4.00 for Windows (GraphPad Software, San Diego, CA). Differences were considered significant at $P<0.05$.

\section{Results}

\section{Description of the Assay}

CellTracker-labeled MSC-4E cells adhered to the surface of kidney sections in an ostensibly random manner (Figure 1, A-E), as singular entities, with no detectable clustering of the cells or preferential adhesion to specific zones. Higher magnification and co-localization studies of adhered MSC-4E cells and Tie-2 GFP labeled vascular endothelium revealed that the majority of adhered cells were lodged in the proximity of vascular beds, either arterioles or capillaries, including glomeruli (Figure 1, $\mathrm{F}-\mathrm{H}$ ). On the other hand, adhesion was asymmetric with much higher numbers detected on the ischemic versus
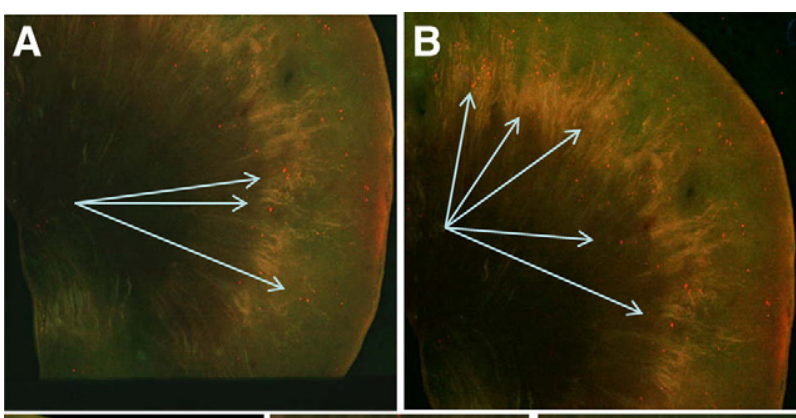
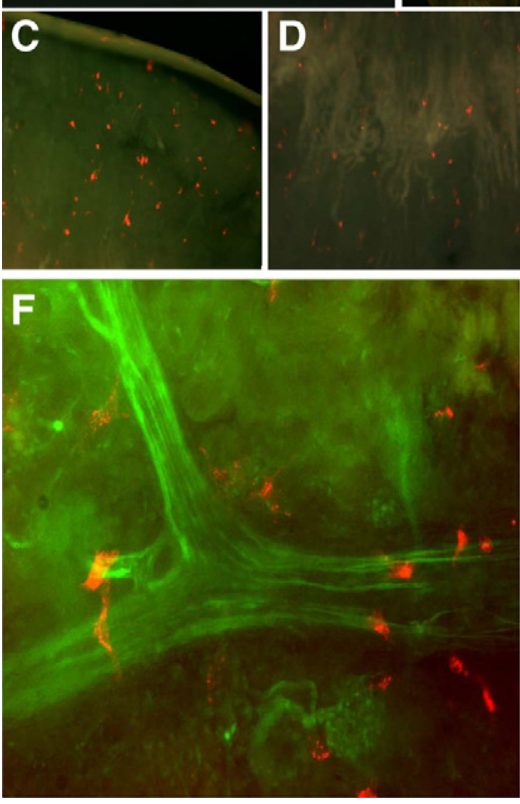

Figure 1. A gallery of images depicting MSC-4E cell adhesion to renal sections A-B: Panoramic views of MSC-4E cell adhesion, stained red with CellTracker CM-Dil, to kidney sections; original magnification $\times 40$. Arrows indicate sites of fluorescently tagged MSC-4E cell adhesion. C-E: MSC-4E cells, stained red with CellTracker CM-DiI, adhered to the cortex, cortico-medullary junction, and medulla, respectively; magnification $\times 10$. $\mathbf{F}-\mathbf{H}$ : MSC-4E cell adhesion to postischemic sections obtained from Tie-2/GFP mice. Note the proximity of adhesion to the vascular tree $(\mathbf{F}, \mathbf{G})$ and glomeruli $(\mathbf{F}, \mathbf{H})$; original magnification $\times 40$. 
A

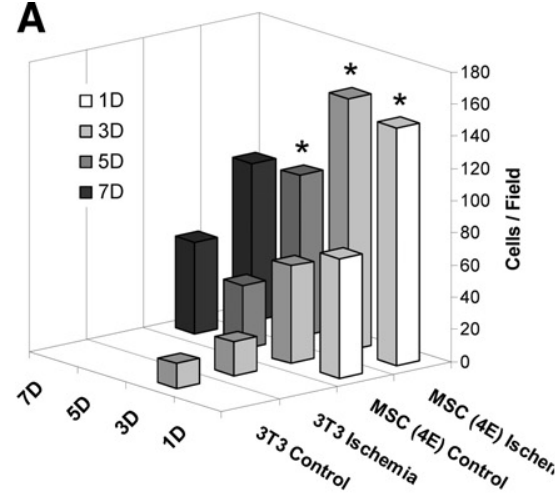

B

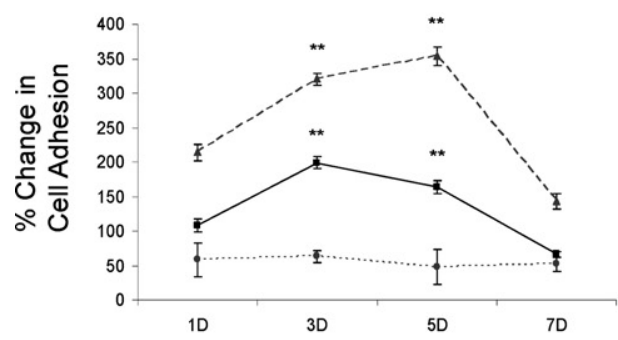

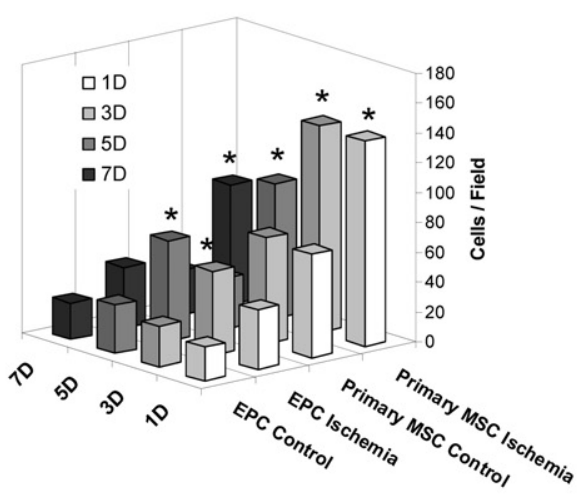

Medulla

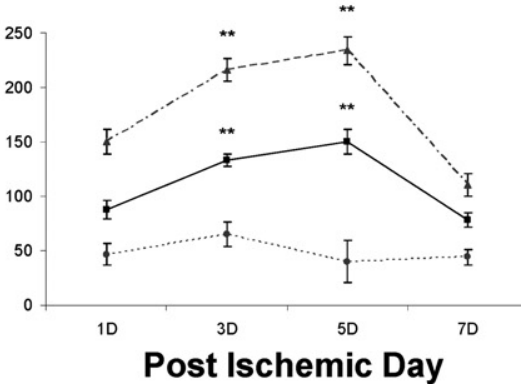

Figure 2. Dynamics of stem/progenitor cell adhesion to postischemic versus control kidney sections. A: Global adhesion of primary and cloned (4E cells) MSC, EPC, and 3T3 fibroblasts to control and ischemic kidney sections on days [D] $1,3,5$, and 7 postischemia. Data are presented as total cell adhesion to cortex, medulla, and capsule. ${ }^{*} P<0.05$ vs. control sections; $n=$ 6. B: Percent increase in MSC-4E cell adhesion to postischemic kidney (as compared with contralateral kidney) cortex, medulla, and renal capsule (solid line) and the percent increase in adhesion after cRGD treatment (hashed line). The attenuation of MSC-4E cell adhesion to postischemic sections on treatment with the CXCR4 antagonist AMD3100

(dotted line). ${ }^{*} P<0.05$ vs. 3D, 5D, and 7D; ${ }^{* *} P<0.05$ vs. $1 \mathrm{D}$ and $7 \mathrm{D} ; n=6$. nonischemic side, in the cortex, medulla and renal capsule (Figure 2, A-B). Adhesion of MSC-4E cells to renal sections, both at the cortical and medullary areas, was maximal on days 3 and 5 postischemia, when adhesion increased twofold in the cortex and by $150 \%$ in the medulla, as compared with adhesion in nonischemic kidney sections. When sections were obtained from kidneys harvested 7 days postischemia, MSC-4E cell adhesion was on a decline. In contrast, adhesion to the renal capsule was maximal, with a twofold increase, compared with nonischemic kidney, on day 1 postischemia and significantly declined afterward (Figure 2). The fraction of presented cells that adhered to the capsule, cortical and medullary areas increased from $8.1 \%$ in control kidney sections to $18.6 \%$ in postischemic kidney sections. Adhesion of primary cultures of MSC obtained from adult kidneys (Figure 2) was similar to that of cloned MSC-4E cells. When EPCs (isolated from bone marrow) were used, adhesion to kidney sections increased twofold after ischemic injury, maximum adhesion was detected 3 and 5 days postischemia (Figure 2), but the net adhesion was two- to threefold lower than MSC adhesion (Figure 2). In contrast to this, 3T3 cells exhibited no predilection to the ischemic kidney and displayed approximately 1/10 level of adhesion observed with MSC (Figures 2 and 3, A-B). Adhered MSC-4E cells expressed specific markersCD29 and CD44 (Figure 4).

\section{Dependence of Adhesion on the CXCR4-SDF-1 Interaction}

One of the critical chemokine axes governing attraction and adhesion of stem/progenitor cells to niches is SDF-1 interaction with CXCR4. ${ }^{26,27}$ The observed dynamics of adhesion, indeed, was associated with the enhancement of SDF-1 expression in the ischemic kidneys, as demonstrated by Togel et al. ${ }^{27}$ Therefore, we inquired whether CXCR4-SDF-1 interaction played a role in the observed
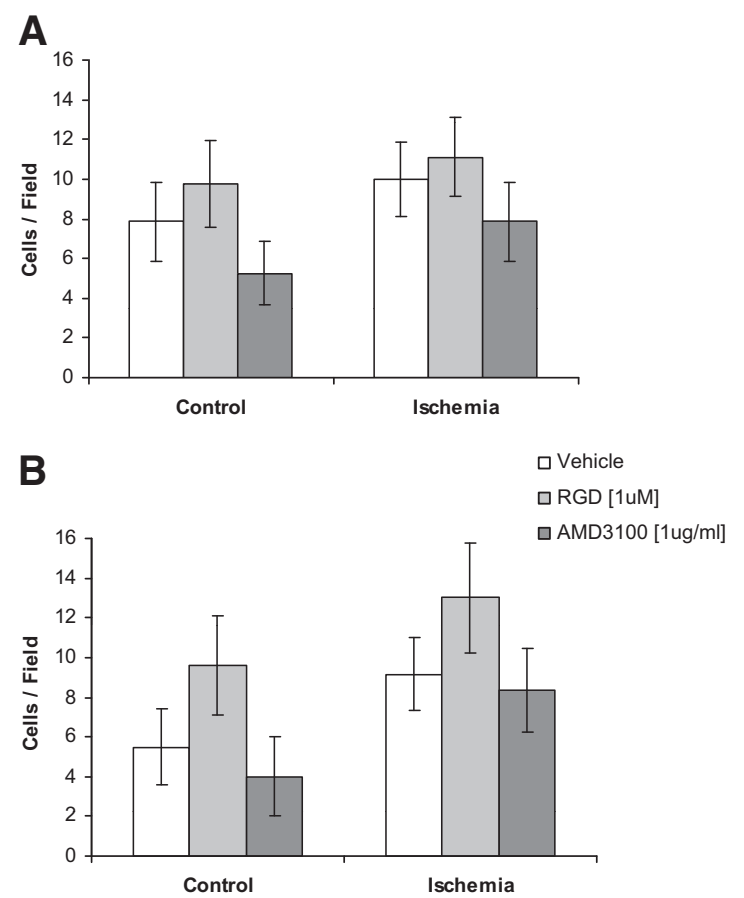

Figure 3. Adhesion of 3T3 fibroblasts to control and postischemic kidney sections. Adhesion data were obtained in the cortex (A) and medulla (B) under basal conditions and after treatment with either AMD3100 or CRGD (for comparison with MSC see Figure 2). No statistical difference between groups; $n=6$. 


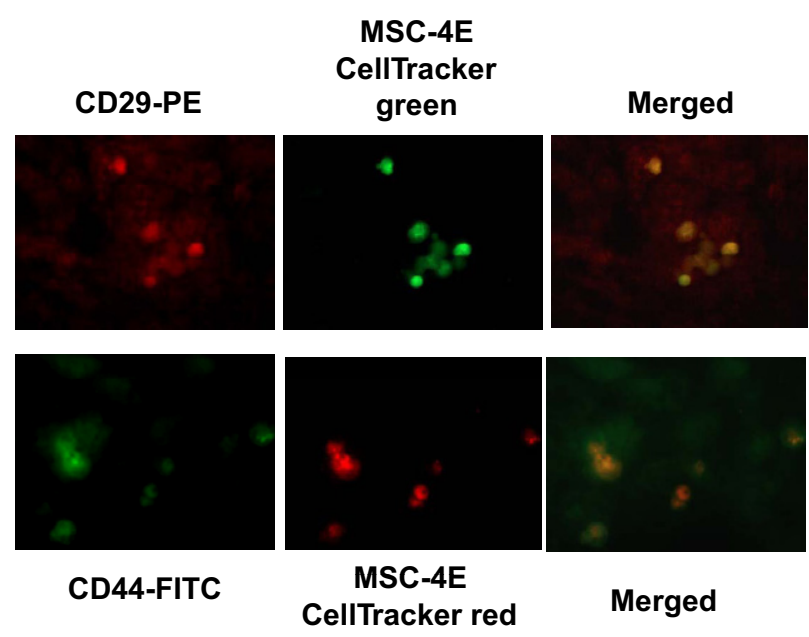

Figure 4. Co-staining of adhered MSC-4E cells with CD29 and CD44. On completion of adhesion assay, sections were fixed and stained with CD29 conjugated to phycoerythrin (CellTracker green labeled cells) or CD44 conjugated to FITC (CellTracker red labeled cells). Note that adhered cells expressed both markers of MSC. Original magnification, $\times 40$.

changes of MSC adhesion to the kidney. Indeed, in the ischemic kidney sections MSC-4E cells tended to colocalize with the expression of SDF-1, which was only faintly detectable in control sections (Figure 5). Toward this end, the next series of experiments used an inhibitor of CXCR4/SDF-1 interaction. Application of AMD3100, a potent CXCR4 antagonist, ${ }^{28}$ to the adhesion assay significantly reduced (by approximately 60 to $70 \%$ ) the number of adhered MSC-4E cells to postischemic kidney sections at the times of their peak adhesion of 3 to 5 days (Figure 2). In fact, pretreatment with AMD3100 resulted in a flattening of the curve of adhesion data at all times postischemia, thus negating the enhanced expression of the
SDF-1/CellTracker
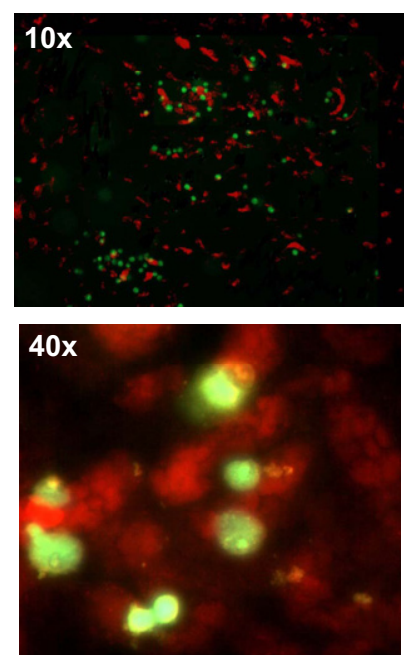

Ischemic
SDF-1/CellTracker
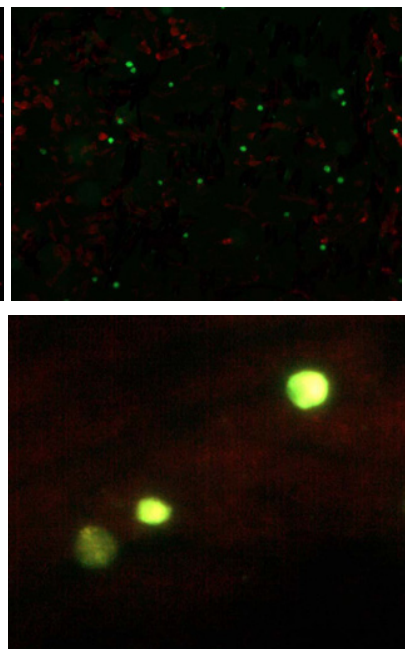

Control
Figure 5. Co-localization of SDF-1 expression with adhered MSC-4E cells Expression of SDF-1 is conspicuous in the ischemic sections and MSC-4E cells tend to co-localize with SDF-1. In contrast, control sections faintly express SDF-1 and MSC-4E cell lodging is not confined to it. Original magnification: top panels $(\times 10)$, lower panels $(\times 40)$.
CXCR4 partner, SDF-1, after ischemia. These data argue in favor of the role of CXCR4-SDF-1 interaction in the used assay and confirms the specificity of the observed adhesion of MSC. The pretreatment of MSC-4E cells with hypoxia caused a robust increase in adherence to ischemic kidney sections at both 1 and 3 days post ischemia (see Supplemental Figure 2 at http://ajp.amjpathol.org). In contrast, tumor necrosis factor- $\alpha$ pretreatment attenuated MSC-4E adhesion to all areas of ischemic kidney sections, consistent with its effect on CXCR4 multimerization.

\section{Caveolin-1 Modulation of Adhesion}

It has been established that SDF-1-induced homodimerization of CXCR4 occurs in caveolae/lipid rafts, ${ }^{29-32}$ and this event is necessary for receptor activation. Mice deficient in caveolin-1 or transgenic mice overexpressing it ${ }^{33}$ were used next to obtain an independent line of evidence on the role of CXCR4 in adhesion. Primary cultures of MSC isolated from kidneys of caveolin- 1 knockout and caveolin-1 transgenic mice were used in the adhesion assay. As shown in Figure 6, A-C, MSC obtained from transgenic mice overexpressing caveolin-1 exhibited more robust adhesion than those obtained from knockout animals. Furthermore, there was no increase in adhesion of caveolin-1 knockout MSC to ischemic kidney. These data are consistent with the requirement for CXCR4 dimerization in caveolae for adhesion to renal binding sites and provides an independent line of evidence for SDF-1/CXCR4 involvement in MSC adhesion.

\section{Occupancy of the Binding Sites with Stem Cells}

It can be envisaged that the observed differences in adhesion to postischemic kidney sections were in part related to the pre-existing occupancy of cortical and medullary binding sites. To overcome this potential drawback of the assay, we used a potent inhibitor of $\alpha 4 \beta 1$ (VLA4)/VCAM-1 interaction, a cRGD. Its fast degradation $^{34}$ made it the preferred choice over neutralizing antibodies. Moreover, this peptide has been shown to inhibit $\alpha 4 \beta 1$ (VLA4)/VCAM- 1 interaction, ${ }^{19}$ as detected using atomic force microscopy. Introduction of CRGD into the assay resulted in a $25 \%$ increase in the number of displaced cells co-expressing CD29 and Sca-1, which were harvested from the culture medium (not shown). The displacement of Sca-1+ cells by CRGD was also observed in Sca-1-GFP kidney sections, where fluorescence intensity decreased by $30 \%$ to $60 \%$ after sections were treated with CRGD peptide (Figure 7, A-D). Moreover, the number of colony-forming units after application of cRGD to kidney sections increased to 15 colonies per 1000 displaced cells (from kidney sections) plated, as compared with one colony that was formed from cells obtained from kidney sections not treated with cRGD. The displaced cells that formed colonies were differentiated into osteocytes and adipocytes, as confirmed by positive alkaline phosphatase, von Kossa, and Oil-Red-O staining, (Figure 7) confirming these cells are indeed authentic MSC. When kidney sections were pretreated with CRGD, it re- 


\section{A}

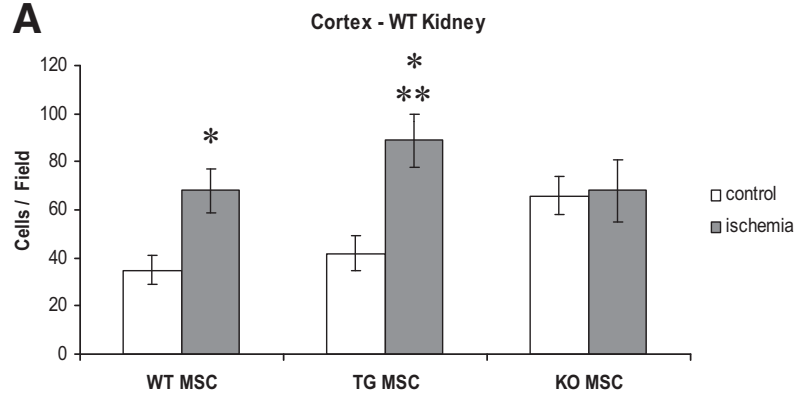

B

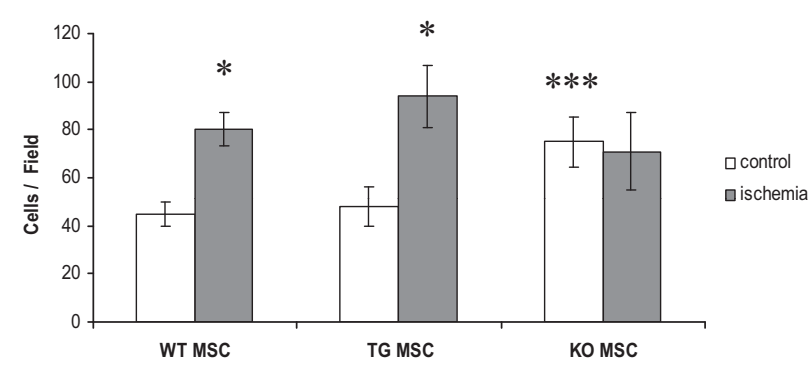

C

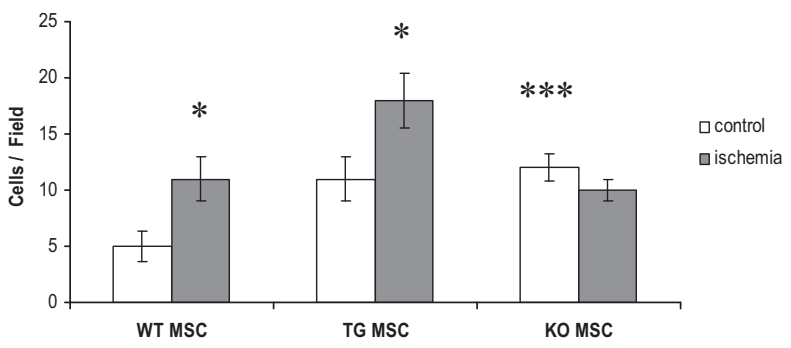

Figure 6. Adhesion assay using MSC obtained from caveolin-1 knockout, transgenic, and wild-type mice. MSC obtained and cloned from transgenic mice overexpressing caveolin-1 demonstrated potentiated adhesion to all regions of the kidney after ischemic insult. MSC void of caveolin-1 demonstrated enhanced adhesion to control sections and no increase in adhesion following ischemic insult. A: cortex; B: medulla; C: capsule. ${ }^{*} P<0.05$ vs control; ${ }^{* *} P<0.05$ vs. ischemia (wild-type \& KO MSC); ${ }^{* * * * *} P<0.05$ vs. control (wild-type \& TG MSC); $n=6$.

sulted in the numerical increase in the firmly adhered MSC-4E cells, both under control and ischemic conditions (Figure 2). cRGD pretreatment was approximately equipotent in inducing the fractional increase in MSC-4E cell adhesion in control and postischemic sections at all times. Adhesion of 3T3 cells showed dependence on neither CXCR4 nor cRGD-dependent integrins (Figure 3).

\section{$\alpha 4 \beta 1$ (VLA4) Dependence of Adhesion}

To elucidate the role of $\alpha 4 \beta 1(\mathrm{VLA} 4)$ in the observed CRGD effects on MSC adhesion, in the next series of experiments we used neutralizing anti-VCAM-1 and antiVLA4 antibodies. Application of both antibodies (either separately or together) in the adhesion assay (Figure 8, A-C) resulted in a nearly twofold decline in the number of adhered MSC-4E cells to ischemic and contralateral kidneys. In addition, there is data indicating the role of $\mathrm{N}$-cadherin in adhesion of stem cells. ${ }^{13}$ To elucidate the role of this adhesion molecule in MSC adhesion to renal binding sites, in the
A

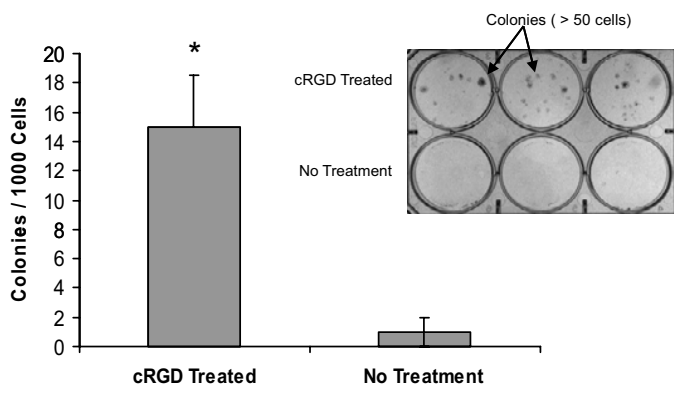

B

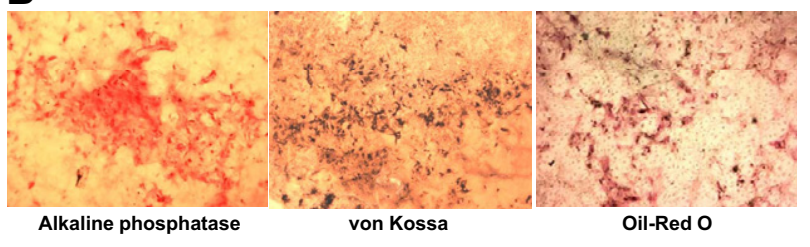

C

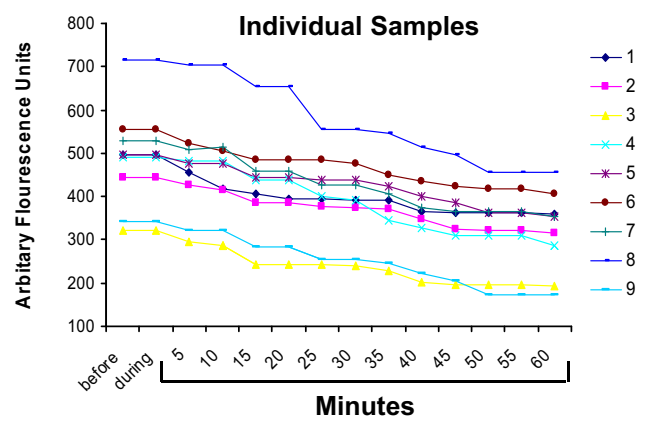

D

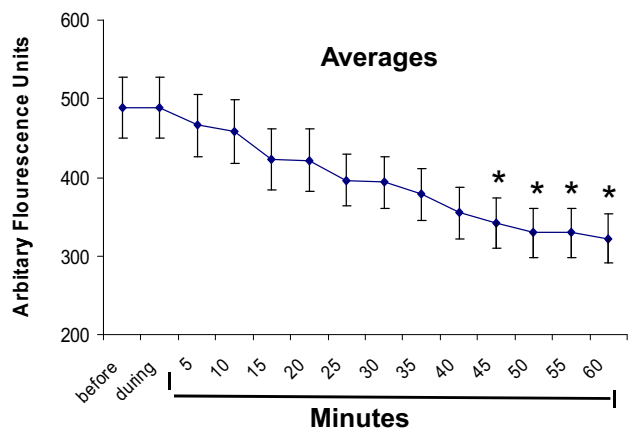

Figure 7. Cyclic RGD peptide induces dislodgement of Sca-1 GFP-positive cells from kidney sections. CFU assay (A) of cells displaced from kidney sections by cRGD, as compared with kidney sections that were not treated with cRGD. Displaced cells that formed colonies demonstrated potential to differentiate into (B) osteocytes and adipocytes. After being subject to differentiating medium, displaced MSC were positive for osteogenic staining including alkaline phosphatase staining (left panel) and von Kossa staining (middle panel), and for adipocytic staining with Oil-Red-O (right panel). Images are viewed under $\times 4$ magnification. Quantitative fluorescence intensity of individual samples (C) and average change (D) of Sca-1 GFP after application of cRGD. Decrease in arbitrary fluorescence is indicative of the release of Sca-1 GFP positive cells from kidney sections. ${ }^{*} P<0.05$ vs. no treatment (A) or baseline intensity $(\mathbf{D})$.

next series of experiments we used neutralizing anti- $\mathrm{N}$ cadherin antibodies. As shown in Figure 8, application of this antibody did not affect MSC adhesion, thus casting doubt that $\mathrm{N}$-cadherin plays an important role in their adhesion to renal binding sites. Combined effect of both $\mathrm{N}$ cadherin and VLA4 neutralizing antibodies was indistinguishable from the inhibitory potency of anti- $\alpha 4 \beta 1$ (VLA4) antibody alone. Immunohistochemistry staining of ischemic 
A

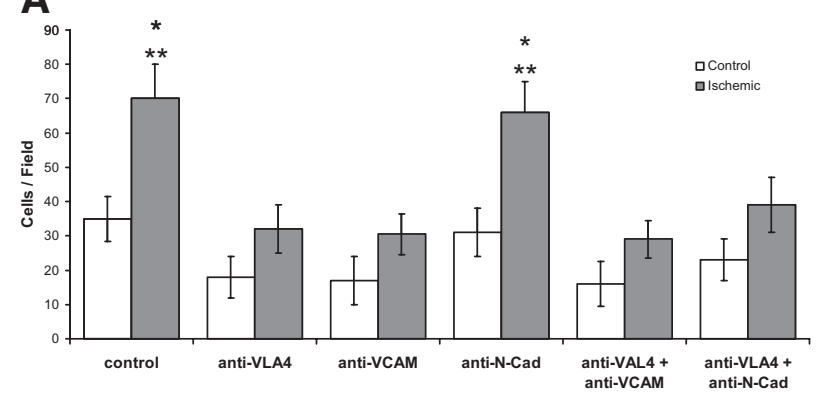

B
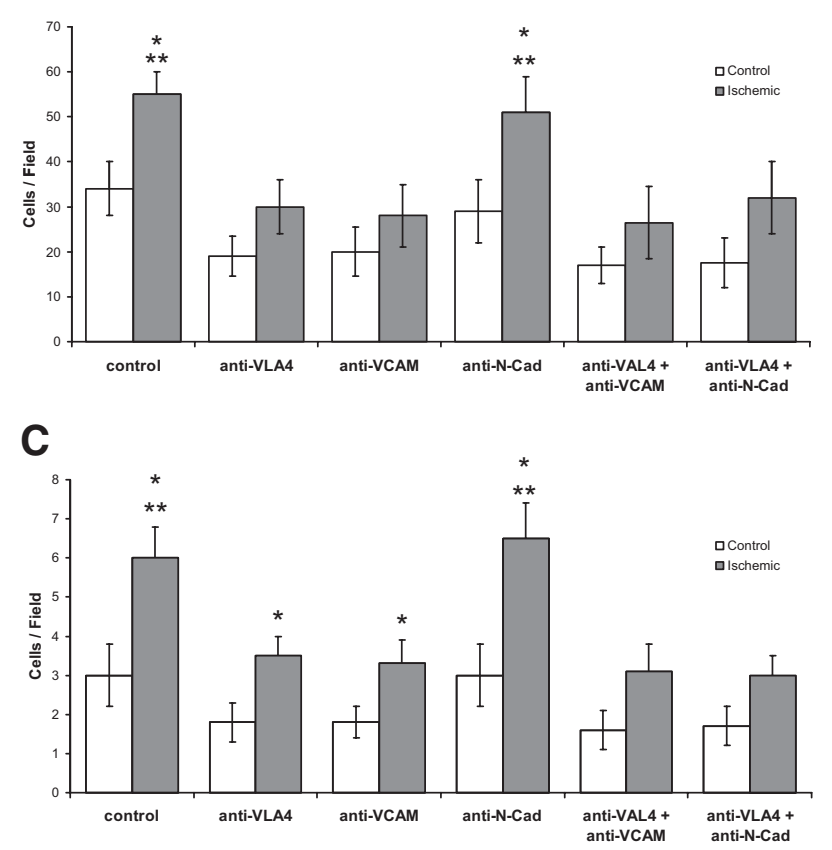

Figure 8. Effect of neutralizing anti-VLA4, anti-VCAM-1, and anti-N-cadherin antibodies on MSC adhesion. Treatment with neutralizing antibodies against VLA4 and VCAM-1 (antibodies applied either separately or together) resulted in attenuation of MSC-4E cell adhesion to all kidney regions and statistically negated the increase in adhesion on ischemic insult in the cortex and medulla. In contrast, application of neutralizing antibodies against N-cadherin had no effect on MSC-4E adhesion. A: cortex; B: medulla; C: capsule, ${ }^{*} P<0.05$ vs. control; ${ }^{* * *} P<0.05$ vs. anti-VLA- 4 , anti-VCAM, and anti-VLA- $4+$ anti-N-Cad/anti-VCAM; $n=6$.

kidney sections showed co-localization of adhered MSC-4E cells to areas positive for fibronectin staining, further demonstrating the possible role of $\beta_{1}$ integrins in MSC adhesion to ischemic kidneys (see Supplemental Figure 3 at http://ajp.amjpathol.org).

\section{Calculated Parameters of Binding Site Occupancy, CXCR4/SDF-1-Dependence of Adhesion, and MSC-Lodging Capacity After Ischemia}

The numerical value of cell-to-kidney adhesion not inhibited in the presence of AMD3100 represents the fraction of CXCR4-independent adhesion. The fraction of CXCR4dependent adhesion was maximal on days 1 and 3 postischemia (Figure 9, A-C) and was increased in the postischemic kidney sections, as compared with control.
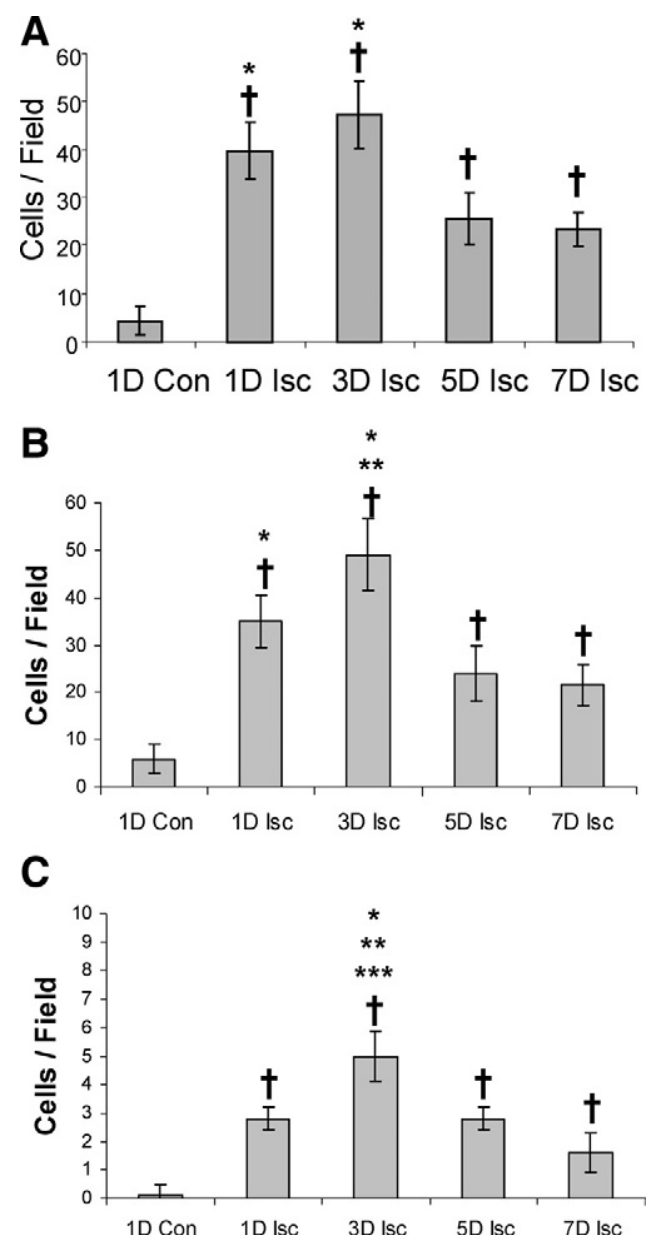

Figure 9. CXCR4/SDF-1-dependent MSC-4E cell adhesion. Chemokine-dependent adhesion to control and postischemia (1, 3, 5, and 7 days[D]) kidney sections, determined as an AMD3100-inhibitable fraction of basal MSC-4E cell adhesion. CXCR4/SDF-1 dependent MSC-4E cell adhesion was enhanced 1 and 3 days after ischemic insult. A: cortex; B: medulla; C: capsule. ${ }^{*} P<0.05$ vs. 7D ischemia; ${ }^{* * *} P<0.05$ vs. 5D ischemia; ${ }^{* * * k} P<0.05$ vs. $1 \mathrm{D}$ ischemia; ${ }^{\dagger} P<0.05$ vs. 1D control; $n=6$.

The numerical value of cRGD-displaceable cells expressed as the difference in MSC-4E cell adhesion between cRGD-pretreated and basal conditions was interpreted as the index of binding sites occupancy (Figure $10, A-C)$. The data indicated that the occupancy of the binding sites with MSC-4E cells was decreased under postischemic conditions. Maximal adhesion of MSC-4E cells to postischemic kidney sections was increased, suggesting the expansion of the sites for their lodging.

The adhesion of MSC-4E cells to sections of cardiac tissue was significantly augmented when sections were obtained from mice receiving adriamycin and developing cardiomyopathy (see Supplemental Figure 4 at http:// ajp.amjpathol.org), an effect that was blocked with the CXCR4 inhibitor AMD3100 and neutralizing antibodies against VLA4 and $\mathrm{N}$-cadherin (an effect not detectable in ischemic kidney sections). The data suggest that the assay used may have a broader usage and may disclose variations in adhesive interactions in different tissues. 


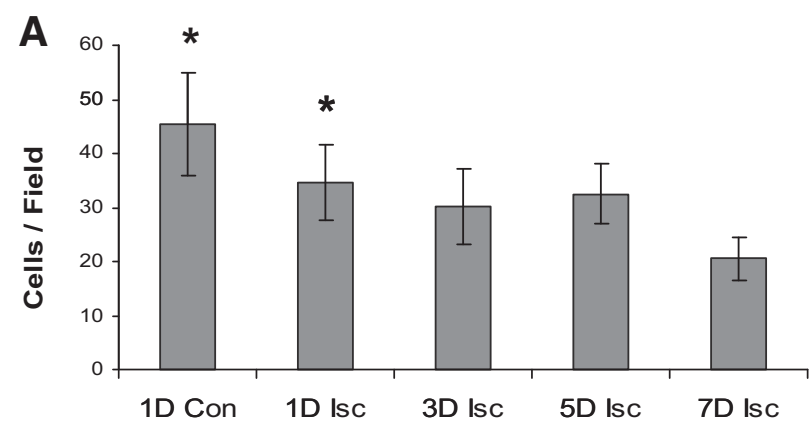

B
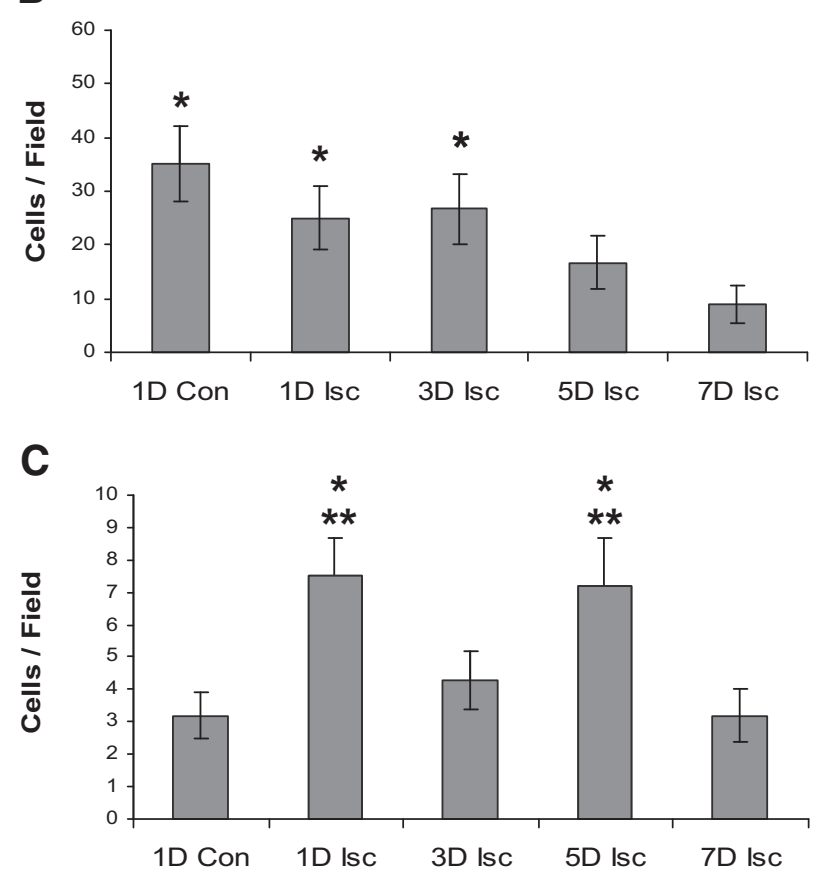

Figure 10. Integrin-dependent MSC-4E cell adhesion. Integrin-dependent adhesion to control and postischemia (1, 3, 5, and 7 days [D]) kidney sections, determined by the numerical value of cRGD-displaced cells expressed as the difference between cRGD-pretreated and basal adhesion. Integrin-dependent adhesion progressively decreased with time after ischemic insult in the cortex and medulla. A: cortex; B: medulla; $\mathbf{C}$ : renal capsule. ${ }^{*} P<0.05$ vs. 7D ischemia; ${ }^{* *} P<0.05$ vs. $1 \mathrm{D}$ control; $n=6$.

\section{Discussion}

Data presented herein demonstrated that adhesion of MSC to ex vivo renal parenchyma is partially CXCR4-SDF1 -dependent and governed in part by the $\beta 1$-integrins and $\alpha 4 \beta 1$ (VLA4)/VCAM- 1 interaction, but not by N-cadherin. Moreover, adhesion of MSC was much higher than that of 3T3 cells or EPC, suggesting that these differences are reflective of the larger capacity of MSC lodging sites (approximately 50 times larger) or a nonspecific adhesion of 3T3 cells. Stem/progenitor cell adhesion to the cortical and medullary parenchyma of the kidney was nearly equal. There was a predilection of adhesion to the perivascular areas, suggesting the existence of the perivascular lodging sites. Adhesion to the postischemic kidneys was significantly enhanced compared with control nonischemic kidneys, consistent with the increase in the capacity of stem cell lodging sites. All these adhesive interactions reproduce the known characteristics of stem cell-to-niche binding. Admittedly, the above constellation of adhesion partners is rather nonspecific and, perhaps, other, much more specific, but as yet unknown partners exist, but the propensity of MSC to lodge at perivascular location in the cortex and medulla, much exceeding the binding of 3T3 cells or EPC, suggests that these sites may at least overlap with MSC niche(s).

While the hematopoietic stem cell niche in the bone marrow has been thoroughly characterized, it has a conspicuously abstract nature in the kidney. A similar approach to methods described here in studying stem cell niches has been recently explored by Mayack et $\mathrm{al}^{35}$ in which osteoblastic niche cells were studied in vitro to determine the differences in accumulation of hematopoietic stem and progenitor cells to young versus aged niches. Our attempt to "visualize" the stem/progenitor cell niche(s) has brought about a clear picture of the distribution of these cells adhering to the kidney. The question is: Does the adhesion pattern faithfully depict the topography of niches? The fact that adhesion of MSC was partially dependent on CXCR4-SDF- 1 and $\alpha 4 \beta 1$ (VLA4)/ VCAM-1 interactions, characteristic of attraction and firm attachment of stem cells to niches, and that this was not the case with adhesion of 3T3 and EPC, argues in favor of the faithfulness of the assay. It should be noted, however, that this adhesion profile may be organ-dependent, since in the ischemic myocardium $\alpha 4 \beta 1$ (VLA4) integrin-mediated engraftment after intramyocardial injection dominated over CXCR4-dependent. ${ }^{36}$ We have not detected foci of nested multicellular adhesion, rather adhesion appeared relatively random throughout the kidney and usually contained single or double cells. In fact, this pauci-cellular distribution appears to be the general property of many stem cell niches. ${ }^{4,37}$ Although these data are consistent with findings by others, it cannot be ruled out at this time that our ex vivo surface adhesion model neglects a more complex three-dimensional architecture of adhesion occurring in vivo. In addition, it cannot be excluded that the assay results in a blurring of the borders of niches due to the diffusion of niche-specific chemoattractants into the culture medium, thus reducing their gradients and potentially obscuring the visualization of discreet topographical structures. Notwithstanding these potential drawbacks, the presented adhesion assay may be of value in disclosing the localization, capacity, and chemoattractant specificity of niches. The data indicate that the CXCR4/SDF-1-dependent adhesion is increased, integrin-dependent adhesion is decreased, the occupancy of MSC niches is decreased and the capacity of MSC niches is expanded after renal ischemia. The adhesion assay may also provide insight into conditions that modify the adhesion characteristics of stem cells, such as hypoxic or tumor necrosis factor- $\alpha$ preconditioning resulting in increased or decreased adhesion, respectively (see Supplemental Figure 2 at http://ajp.amjpathol.org).

One of the topographical structures that did emerge as a preferred adhesion site was represented by perivascular spaces. There is growing awareness of the existence of a vascular niche in the bone marrow, ${ }^{38}$ as well as in 
peripheral organs. ${ }^{39}$ Perivascular localization of a significant number of adhered MSC (Figure 1) may be indicative of the existence of such a niche in the kidney. It has been proposed that the basement membrane serves as an enhancer of signaling by SDF-1. ${ }^{38}$ Since MSC showed the preference toward adhering to perivascular spaces, this predilection may be explained by the concept that only cells which are unable to generate components of the basement membrane may require vascular niche. ${ }^{39}$

Another relatively well-defined low-capacity site of preferential adhesion was identified in the renal capsule. This compartment attracted MSC to the CXCR4-dependent site of MSC residence. ${ }^{40}$

The capacity of MSC lodging sites, at least in part overlapping with niches, appeared to increase after renal ischemia/reperfusion, reaching its maximum on days 3 to 5 and later returning to the baseline. The questions related to the capacity of niches have come into focus of investigations of cancer cells, which may create their own niche and/or hijack pre-existing ones. ${ }^{41}$ Moreover, first evidence linking stem cell niches with disease initiation and progression has arrived from studies of primary myelofibrosis, which is associated with an imbalance between endosteal and vascular niches resulting in clonal cell proliferation. ${ }^{42}$ In the case of the kidney, the ultimate purpose of expanding the capacity of niches after ischemic injury is not known, although a tentative explanation may link it to facilitating the process of maturation of stem/progenitor cells for their participation in tissue regeneration.

In conclusion, we describe here an ex vivo adhesion assay in which stem cells (the bait) are presented to kidney section to help visualize their specific binding partners (presumed to be niches). Studies showed that adhesion of MSC is CXCR4 and $\alpha 4 \beta 1$ (VLA4) integrinsensitive, $\mathrm{N}$-cadherin-insensitive, and that specific adhesion exceeds by about 10-fold the adhesion of non-stem cells. Moreover, the assay used allowed assess to the virtual capacity of stem cell adhesion sites, possibly, at least, in part overlapping with niches in the kidney. In addition, the adhesion assay described here may also be used to determine cell adhesion characteristics in other models, as demonstrated here with cardiac tissue (see Supplemental Figure 4 at http://ajp.amjpathol.org).

\section{References}

1. Schofield R: The relationship between the spleen colony-forming cell and the hematopoietic stem cell. Blood Cells 1978, 4:7-25

2. Moore K, Lemischka I: Stem cells and their niches. Science 2006, 311:1880-1885

3. Xie T, L Li: Stem cells and their niche: an inseparable relationship. Development 2007, 134:2001-2006

4. Morrison S, Spradling A: Stem cells and niches: mechanisms that promote stem cell maintenance throughout life. Cell 2008, 132:598611

5. Zhang J, Niu C, Ye L, Huang H, He X, Tong W, Ross J, Haug J, Johnson T, Feng J, Harris S, Wiedemann L, Mishina Y, Li L: Identification of the haematopoietic stem cell niche and control of the niche size. Nature 2003, 425: 836-841

6. Calvi L, Adams G, Weibrecht K, Weber J, Olson D, Knight M, Martin R, Schipani E, Divieti P, Bringhurst F, Milner L, Kronenberg H, Scad- den D: Osteoblastic cells regulate the haematopoietic stem cell niche. Nature 2003, 425:841-846

7. Fuchs E, Tumbar T, Guasch G: Socializing with the neighbors: stem cells and their niche. Cell 2004, 116:769-778

8. Oliver J, Maarouf O, Cheema F, Martens T, Al-Awqati Q: The renal papilla is a niche for adult kidney stem cells. J Clin Invest 2004, 114:795-804

9. Maeshima A, Yamashita S, Nojima Y: Identification of renal progenitor-like tubular cells that participate in the regeneration processes of the kidney. J Am Soc Nephrol 2003, 14:3138-3146

10. Challen G, Bertoncello I, Deane J, Ricardo S, Little M: Kidney side population reveals multilineage potential and renal functional capacity but also cellular heterogeneity. J Am Soc Nephrol 2006, 17:18961912

11. Patschan D, Michurina T, Shi H, Dolff S, Brodsky S, Vasilieva T, Cohen-Gould L, Winaver J, Chander PN, Enikolopov G, Goligorsky MSL: Normal distribution and medullary-to-cortical shift of nestinexpressing cells in acute renal ischemia. Kidney Internt 2007, 71: $744-754$

12. Potten C, Owen G, Booth D: Intestinal stem cells protect their genome by selective segregation of template DNA strands. J Cell Sci 2002, 115:2381-2388

13. Kaplan R, Psaila B, Lyden D: Niche-to-niche migration of bonemarrow-derived cells. Trends Mol Med 2007, 13:72-81

14. Oostendorp R, Dormer P: VLA4-mediated interactions between normal human hematopoietic progenitors and stromal cells. Leuk Lymphoma 1997, 24:423-435

15. Scott L, Priestley G, Papayannopoulou T: Deletion of $\alpha 4$-integrins from adult hematopoietic cells reveals roles in homeostasis, regeneration and homing. Mol Cell Biol 2003, 23:9349-9360

16. Papayannopoulou $\mathrm{T}$ : Current mechanistic scenarios in hematopoietic stem/progenitor cell mobilization. Blood 2004, 103:1580-1585

17. Hu Y, Davison F, Zhang Z, Xu Q: Endothelial replacement and angiogenesis in arteriosclerotic lesions of allografts are contributed by circulating progenitor cells. Circulation 2003, 108:3122-3127

18. Jin H, Aiyer A, Su J, Borgstrom P, Stupack D, Friedlander M, Varner $\mathrm{J}$ : A homing mechanism for bone marrow-derived progenitor cell recruitment to the neovasculature. J Clin Invest 2006, 116:652-662

19. Zhang X, Deleone D, Li H, Noiri E, Moy VT, Goligorsky MS: Leukocyte adhesion to endothelial cells, adhesive energy and transmigration are inhibited by a cyclic RGD peptide. Am J Physiol Renal 2004, 286: H359-H367

20. US Department of Health and Human Services Public Health Services $(\mathrm{NIH})$. Guide for the Care and Use of Laboratory Animals. NIH Publication No. 86-23, 1985

21. Plotkin MD, Goligorsky MS: Mesenchymal cells from adult kidney support angiogenesis and differentiate into multiple interstitial cell types including erythropoietin-producing fibroblasts. Am J Physiol Renal Physiol 2006, 291:F902-F912

22. Hanson P, Mathews V, Marrus S, Graubert TA: Enhanced green fluorescent protein targeted to the Sca-1 (Ly-6A) locus in transgenic mice results in efficient marking of hematopoietic stem cells in vivo. Exp Hematol 2003, 31:159-167

23. da Silva Meirelles L, Chagastelles PC, Nardi NB: Mesenchymal stem cells reside in virtually all post-natal organs and tissues. J Cell Sci 2006, 119:2204-2213

24. Arriero M, Brodsky SV, Gealekman O, Lucas PA, Goligorsky MS: Adult skeletal muscle stem cells differentiate into endothelial lineage and ameliorate renal dysfunction after acute ischemia. Am J Physiol: Renal 2004, 287:F621-F627

25. Chen J, Park HC, Addabbo F, Ni J, Pelger L, Lil Houwei E, Plotkin M Goligorsky MS: Kidney-derived mesenchymal stem cells contribute to vasculogenesis, angiogenesis and endothelial repair. Kidney Inter 2008, 74:879-889

26. Sainz J, Sata M: CXCR4, a key modulator of vascular progenitor cells. Arterioscler Thromb Vasc Biol 2007, 27:263-265

27. Togel F, Isaak J, Hu Z, Weiss K, Westenfelder C: Renal SDF-1 signals mobilization and homing of CXCR4-positive cells to the kidney after ischemic injury. Kidney Internat 2005, 67:1772-1784

28. Zemani F, Silvestre J-S, Fauvel-Lafeve F, Bruel A, Vilar J, Bieche I, Laurendeau I, Galy-Fauroux I, Fischer AM, Boisson-Vidal C: Ex vivo priming of endothelial progenitor cells with SDF-1 before transplantation could increase their proangiogenic potential. Arterioscl Thromb Vasc Biol 2008, 28:644-650 
29. van Buul J, Voermans C, van Gelderen, Anthony E, van der Schoot C, Hordijk P. Leukocyte-endothelium interaction promotes SDF-1-dependent polarization of CXCR4. J Biol Chem 2003, 278:30302-30310

30. Wysoczynski M, Reca R, Ratajczak J, Kucia M, Shirvaikar N, Honczarenko M, Mills M, Wanzeck J, Janowska-Wieczorek A, Ratajczak M: Incorporation of CXCR4 into membrane lipid rafts primes homingrelated responses of hematopoietic stem/progenitor cells to an SDF-1 gradient. Blood 2005, 5:40-48

31. Sbaa E, De Wever J, Martinive P, Bouzin C, Frerart F, Balligand JL, Dessy C, Feron O: Caveolin plays a central role in endothelial progenitor cell mobilization and homing in SDF-1-driven postischemic vasculogenesis. Circ Res 2006, 98:1219-1227

32. Toth $\mathrm{P}$, Ren D, Miller R: Regulation of CXCR4 receptor dimerization by the chemokine SDF-1a and HIV-1 coat protein gp120. J Pharmacol Exp Ther 2004, 310:8-17

33. Mercier E, Jasmin J-F, Pavlides S, Minetti C, Flomenberg N, Pestell R, Frank P, Sotgia F, Lisanti M: Clinical and translational implications of the caveolin gene family: lessons from mouse models and human genetic disorders. Lab Invest 2009, 89:614-623

34. Noiri E, Goligorsky MS, Som P: Radiolabeled RGD peptides as diagnostic tools in acute renal failure and tubular obstruction. J Am Soc Nephrol 1996, 7:2682-2688

35. Mayack SR, Shadrach JL, Kim FS, Wagers AJ: Systemic signals regulate ageing and rejuvenation of blood stem cell niches. Nature 2010, 463(28):495-501

36. Ip J, Wu Y, Huang J, Zhang L, Pratt R, Dzau V: Mesenchymal stem cells use integrin beta-1 not CXC chemokine receptor 4 for myocardial migration and engraftment. Mol Biol Cell 2007, 18:2873-2882

37. Jones $D$, Wagers A: No place like home: anatomy and function of the stem cell niche. Nature Rev: Mol Cell Biol 2008, 9:11-21

38. Kopp HG, Avecilla S, Hooper A, Rafii S: The bone marrow vascular niche: home of HSC differentiation and mobilization. Physiol 2005, 20:349-356

39. Nikolova G, Strilic B, Lammert E: The vascular niche and its basement membrane. Trends Cell Biol 2007, 17:19-25

40. Park HC, Kuo K, Ni J, Ratliff B, Singh N, Chander P, Goligorsky MS Renal capsule as a stem cell niche. J Am Soc Nephrol 2008, 19:104A

41. Sipkins D, Wei X, Wu JW, Runnels JM, Côté D, Means TK, Luster AD, Scadden DT, Lin CP: In vivo imaging of specialized bone marrow endothelial microdomains for tumor engraftment. Nature 2005, 435: 969-973

42. Lataillade JJ, Olivier PL, Hasselbalch H, Uzan G, Jasmin C, Martyre MC, Le Bousse-Kerdiles MC: Does primary myelofibrosis involve a defective stem cell niche? From concept to evidence. Blood 2008, 112:3026-3035 